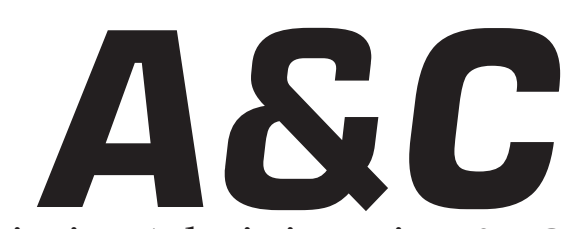

Revista de Direito Administrativo \& Constitucional

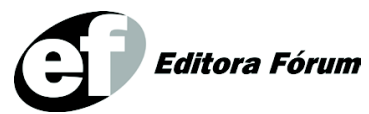

ISSN $1516-3210$ 


\section{A\&C REVISTA DE DIREITO ADMINISTRATIVO E CONSTITUCIONAL}

IPDA

Instituto Paranaense

de Direito Administrativo

Direção Geral

Romeu Felipe Bacellar Filho

Direção Editorial

Paulo Roberto Ferreira Motta

Direção Executiva

Emerson Gabardo

Conselho de Redação

Edgar Chiuratto Guimarães

Adriana da Costa Ricardo Schier

Célio Heitor Guimarães

\section{Conselho Editorial}

Adilson Abreu Dallari

Alice Gonzáles Borges

Carlos Ari Sundfeld

Carlos Ayres Britto

Carlos Delpiazzo

Cármen Lúcia Antunes Rocha

Celso Antônio Bandeira de Mello

Clèmerson Merlin Clève

Clóvis Beznos

Enrique Silva Cimma

Eros Roberto Grau

Fabrício Motta

Guilhermo Andrés Muñoz (in memoriam)

Jaime Rodríguez-Arana Muñoz

Jorge Luís Salomoni

José Carlos Abraão
José Eduardo Martins Cardoso
José Luís Said
José Mario Serrate Paz
Juan Pablo Cajarville Peruffo
Juarez Freitas
Julio Rodolfo Comadira
Luís Enrique Chase Plate
Lúcia Valle Figueiredo
Manoel de Oliveira Franco Sobrinho
(in memoriam)
Marçal Justen Filho
Marcelo Figueiredo
Márcio Cammarosano
Maria Cristina Cesar de Oliveira

Nelson Figueiredo

Odilon Borges Junior

Pascual Caiella

Paulo Eduardo Garrido Modesto

Paulo Henrique Blasi

Paulo Neves de Carvalho (in memoriam)

Paulo Ricardo Schier

Pedro Paulo de Almeida Dutra

Regina Maria Macedo Nery Ferrari

Rogério Gesta Leal

Rolando Pantoja Bauzá

Sérgio Ferraz

Valmir Pontes Filho

Yara Stropa

Weida Zancaner

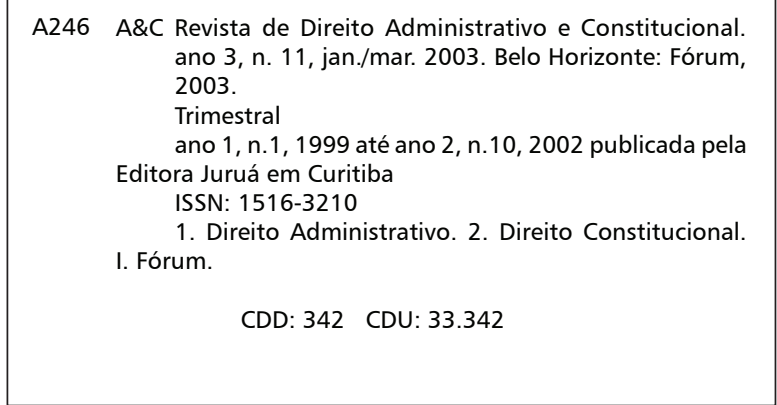

(c) Editora Fórum Ltda. 2006

Todos os direitos reservados. É proibida a reprodução total ou parcial, de qualquer forma ou por qualquer meio eletrônico ou mecânico, inclusive através de processos xerográficos, de fotocópias ou de gravação, sem permissão por escrito do possuidor dos direitos de cópias (Lei $n^{\circ}$ 9.610, de 19.02.1998).

\section{Editora Fórum Ltda}

Av. Afonso Pena, 2770 - 15\%16ªndar - Funcionários

CEP 30130-007 - Belo Horizonte/MG - Brasil

Tel.: 08007043737

Internet: www.editoraforum.com.br

e-mail: editoraforum@editoraforum.com.br
Editor responsável: Luís Cláudio Rodrigues Ferreira Projeto gráfico e diagramação: Luis Alberto Pimenta Revisora: Olga M. A. Sousa

Pesquisa jurídica: Fátima Ribeiro - OAB/MG 74868

Bibliotecária: Alessandra Rodrigues da Silva CRB 2778/MG 6 ${ }^{\text {a Região }}$

Os conceitos e opiniões expressas nos trabalhos assinados são de responsabilidade exclusiva de seus autores.

Impressa no Brasil / Printed in Brazil

Distribuída em todo Território Nacional 


\title{
Participação popular como condição de efetividade da gestão urbano-democrática*
}

\author{
Marcelene Carvalho da Silva Ramos \\ Professora de Direito Constitucional I, do Curso de Direito da FIC - Faculdades Integradas Curitiba. \\ Mestre em Direito do Estado, com concentração em Direito Constitucional pela UFPR- Universidade \\ Federal do Paraná. Procuradora do Estado do Paraná
}

Palavras-chave: Participação popular. Gestão urbana. Democracia. Cidades. Estatuto das Cidades.

\begin{abstract}
O direito à cidade deve ser compreendido como o direito de ter condições dignas de vida, de exercitar plenamente a cidadania, de ampliar os direitos fundamentais, de participar da gestão da cidade, de viver em um meio ambiente ecologicamente equilibrado e sustentável. **
\end{abstract}

Diante das disposições constitucionais inovadoras acerca do desenvolvimento urbano, muito bem secundadas pelas normas gerais estabelecidas pelo Estatuto da Cidade, e ainda, em virtude da Democracia participativa ${ }^{1}$ que foi instaurada a partir da Constituição Federal de 1988, tem-se ambiente propício para a construção do alargamento das formas de participação popular nas políticas de desenvolvimento urbano, com a prossecução da efetividade das normas constitucionais e infra-constitucionais, que dispõem acerca da gestão democrática da cidade e que já integram o ordenamento jurídico pátrio. ${ }^{2}$

Em última ratio, as possibilidades do exercício da cidadania pela participação direta nas instâncias de decisões políticas para a construção e execução das políticas públicas de desenvolvimento urbano, é que

\footnotetext{
* Projeto de Pesquisa aprovado pela COPEX - Coordenadoria de Pós-Graduação, Pesquisa e Extensão das Faculdades Integradas Curitiba, em reunião do Comitê de Pesquisa e Ética, realizada em 15 de março de 2006.

**SAULE JÚNIOR, Nelson apud ROCHA, Julio César de Sá da. Função ambiental da cidade: direito ao meio ambiente urbano ecologicamente equilibrado. São Paulo: Juarez de Oliveira, 1999. p. 30.

Ao lado da democracia representativa, nos termos da Constituição Federal, a teor do que dispõe o art. $1^{\circ}$, $\S 2^{\circ}, \mathrm{CF}$.

2 Ainda acerca da democracia participativa Roberto Mangabeira Unger, na Folha de S.Paulo de 27 set. 2005, A-2, em artigo intitulado "Aprofundar a democracia": "(...) Falseiam a tese da radicalização democrática os que a denunciam como ataque contra a democracia representativa. O que ela quer é tornar essa democracia efetiva, em meio aos extremos de desigualdade de que sofremos. (...) Não há democracia sem participação."
}

A \& C R. de Dir. Administrativo e Constitucional, Belo Horizonte, ano 6, n. 25, p. 95-108, jul./set. 2006 
contribuirão efetivamente com a construção da gestão democrática das cidades.

Sob o ponto de vista do arcabouço normativo, é de se destacar que as normas gerais acerca do tema estão insculpidas nos artigos $2^{\circ}$, incisos II e XIII e $4^{\circ}$, inciso III, alínea $f$, e $\S 3^{\circ}$, e ainda, artigos 27 e $\S 2^{\circ}, 40, \S 1^{\circ}$, I 37 , parágrafo único, da Lei $\mathrm{n}^{\circ} 10.257 / 01$. Assume especial relevo o Capítulo IV, que nos artigos 43 a 45 tratam da Gestão Democrática da Cidade.

Importante ainda ressaltar que a gestão urbana democrática, por meio da participação popular, tanto compõe o rol das diretrizes gerais para a execução da política urbana como constitui instrumento de política urbana.

Com efeito, assim preceitua o artigo $2^{\circ}$, II, do Estatuto da Cidade, no Capítulo I, que traça as Diretrizes Gerais da política urbana: "A política urbana tem por objetivo ordenar o pleno desenvolvimento das funções sociais da cidade e da propriedade urbana, mediante as seguintes diretrizes gerais: (...) II - gestão democrática por meio da participação da população e de associações representativas dos vários segmentos da comunidade na formulação, execução e acompanhamento de planos, programas e projetos de desenvolvimento urbano;". E no inciso XIII: "audiência do Poder Público Municipal e da população interessada nos processos de implantação de empreendimentos ou atividades com efeitos potencialmente negativos sobre o meio ambiente natural ou construído, o conforto ou a segurança da população; (...).”

De sua vez, dispõe o artigo $4^{\circ}$, III, $f, \mathrm{~V}, s$ e $\S 3^{\circ}$, do Estatuto da Cidade, no Capítulo II, que trata dos Instrumentos de Política Urbana: "Para os fins desta Lei, serão utilizados, entre outros instrumentos: (...) III - planejamento municipal, em especial: (...) f- gestão orçamentária participativa; (...). V - s) referendo popular e plebiscito (...) $\S 3^{\circ}$. Os instrumentos previstos neste artigo que demandam dispêndio de recursos por parte do Poder Público Municipal devem ser objeto de controle social, garantida a participação de comunidades, movimentos e entidades da sociedade civil”. Infere-se do ordenamento jurídico, que a forma determinada para a consecução democrática da gestão urbana deve estar caracterizada pela participação da população ${ }^{3}$ e de associações representativas dos vários segmentos comunitários sendo que, o âmbito de atuação popular é o

\footnotetext{
3 Cf. PATARO, 2003, p. 97-127: "(...) Já o princípio da participação deve orientar toda atuação pública, com vistas a gradual ampliação de políticas inclusiva, vez que 'está diretamente referido à expansão da consciência social e ao natural anseio de influir de algum modo nas decisões de poder que repercutirão sobre as pessoas interessadas.' (Diogo Figueiredo Moreira Neto: Mutações...)."
} 
da formulação, planejamento, execução e acompanhamento de planos, programas e projetos de desenvolvimento urbano.

Constata-se, também, a participação popular na gestão do orçamento público, ${ }^{4}$ influindo diretamente na distribuição e aplicação das verbas destinadas à implementação das políticas públicas de desenvolvimento urbano, selecionando os programas e projetos prioritários ao bem-estar da população, bem assim, a garantia do exercício do controle social dos recursos orçamentários por meio da participação comunitária e dos movimentos sociais organizados, e ainda, das entidades da sociedade civil.

A publicidade é outro mecanismo propiciador ao controle democrático da ação urbanística estatal ${ }^{5}$ e encontra previsão no art. $27, \S 2^{\circ},{ }^{6}$ do Estatuto da

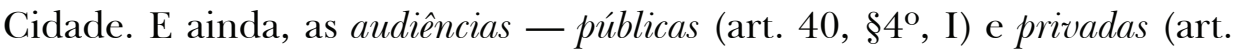
37, parágrafo único) - constituem âmbitos de atuação popular, por meio da participação na elaboração do Plano Diretor da cidade ou ainda, pelo conhecimento dos documentos que integram o Estudo de Impacto de Vizinhança.

Também o art. $40, \S 4^{\circ}$, no inciso II, traz mecanismo de publicidade de documentos e informações produzidas no que se referem ao Plano Diretor. $^{7}$

A fim de garantir a gestão democrática da cidade, ${ }^{8}$ e portanto, assegurar a participação popular, o artigo 43 do Estatuto da Cidade elenca um rol de instrumentos que devem ser utilizados. São eles: cria-

\footnotetext{
4 PATARO, 2003, p. 118: "(...) Outro importante fenômeno da vivência democrática é o orçamento participativo, realidade em muitos Municípios brasileiros. Originariamente os orçamentos públicos eram cometidos a tecnocratas, que, na maioria das vezes, desconheciam até a realidade do Município, por exemplo. (...)."

5 Cf. Carlos Ari Sundfeld, op. cit., p. 57.

6 "Art. 27: O proprietário deverá notificar sua intenção de alienar o Imóvel, para que o Município, no prazo máximo de trinta dias, manifeste por escrito seu interesse em comprá-lo. Omissis. \$2. O Município fará publicar, em órgão oficial e em pelo menos um jornal local ou regional de grande circulação, edital de aviso da notificação recebida nos termos do caput e da intenção de aquisição do imóvel nas condições da proposta apresentada." "Art. 37.(...) Parágrafo único: Dar-se-á publicidade aos documentos integrantes do EIV, que ficarão disponíveis para consulta, no órgão competente do Poder Público Municipal, por qualquer interessado."

7 "Art. 40. O plano diretor, aprovado por lei municipal, é o instrumento básico da política de desenvolvimento e expansão urbana. ${4^{\circ}}^{\circ}$. No processo de elaboração do plano diretor e na fiscalização de sua implementação, os Poderes Legislativo e Executivo Municipais garantirão: I - a promoção de audiências públicas e debates com a participação da população e de associações representativas dos vários segmentos da comunidade; II - a publicidade quanto aos documentos e informações produzidos:"

8 Vejam-se as recomendações do Ministério das Cidades, na Apresentação do Ministro Márcio Fortes para a $2^{a}$ Conferência Nacional das Cidades: (...) Participação e Controle social: 38. A implementação da gestão democrática na PNDU, conforme item (5) exige compromissos dos poderes executivos e legislativos com: a) o compartilhamento do poder de decisão com a sociedade na definição das políticas dos investimentos públicos; b) o combate as formas de conservadorismo político, clientelismo, interesses particulares e privatistas e a cultura do favor; c) o fortalecimento permanente de atores/sujeitos sociaispolíticos autônomos; d) a organização de sistemas de informação e estruturas institucionais que
} 
ção de órgãos colegiados de política urbana, nos níveis nacional, estadual e municipal; ${ }^{9}$ debates, audiências e consultas públicas $;{ }^{10}$ conferências sobre assuntos de interesse urbano, ${ }^{11}$ nos níveis nacional, estadual e municipal e iniciativa popular de projeto de lei e de planos, programas e projetos de desenvolvimento urbano.

E ainda dispõem os arts. 44 e 45: "Art. 44. No âmbito municipal, a gestão orçamentária participativa de que trata a alínea "f" do inciso III do art. $4^{\circ}$ desta Lei incluirá a realização de debates, audiências e consultas públicas sobre as propostas do plano plurianual, da lei de diretrizes orçamentárias e do orçamento anual, ${ }^{12}$ como condição obrigatória para sua aprovação pela Câmara Municipal. Art 45: Os organismos gestores das regiões metropolitanas e aglomerações urbanas incluirão obrigatória e significativa participação da população e de associações representativas dos vários segmentos da comunidade, de modo a garantir o controle direto de suas atividades e o pleno exercício da cidadania." G.n.

Nessa perspectiva, ressaltam os avanços que a sociedade brasileira alcançou com a constitucionalização da política urbana, em especial pela inscrição dos artigos 182 e 183 na Carta da República de 1988 e ainda, com o advento do Estatuto da Cidade (Lei n $\left.{ }^{\circ} 10.257 / 2001\right)$.

Todavia, tais acontecimentos no plano jurídico significam apenas o ponto de partida e o primeiro passo para a efetivação de uma gestão realmente democrática das cidades. ${ }^{13}$

O caminho é o próprio processo de construção da Democracia pela via da efetiva participação popular, em especial, por meio do alargamento dos espaços públicos não-estatais, porém, institucionais, como as Con-

proporcionem à população o acesso às informações;e) a promoção de um processo contínuo de discussão, negociação e de aprendizado coletivo; f) a constituição de espaços, instrumentos, canais ou instâncias de participação da sociedade;g) o respeito pelas diferenças de pensamento; h) a apresentação de suas propostas de forma clara e transparente; i) a promoção da democratização do Estado para tornálo transparente, descentralizado e assegurando o controle social, sobre as ações governamentais; 39. A gestão democrática exige compromissos das organizações sociais e da população com: a) a mobilização das entidades e da população para o reconhecimento das instâncias de participação e para o debate

9 Acerca da criação de órgãos colegiados, colhem-se as seguintes recomendações da apresentação do Ministro das Cidades para a $2^{a}$. Conferência Nacional: "(...) 40. Para permitir a participação e o controle social, União, estados, municípios, devem promover:a) Constituição democrática de conselhos da cidade, para superar a fragmentação das políticas públicas urbanas através da integração das áreas temáticas e setoriais (desenvolvimento urbano, habitação, saneamento ambiental, transporte, trânsito e mobilidade urbana);(...)."

10 Idem: "(...) d) A implementação de instrumentos previstos no Estatuto da Cidade e Resolução 25/05 do Conselho das Cidades, tais como: debates, audiências públicas; plebiscito, referendos.(...)"

11 Idem sobre a realização de Conferências: "(...) b) Conferências das Cidades, para possibilitar a participação de todos os segmentos da sociedade, com especial atenção aos mais excluídos, e para eleger os membros dos conselhos das cidades;c)Articulação de conselhos e canais de participação existentes em cada esfera da Federação, incluindo também regiões metropolitanas e outros recortes regionais, buscando coordenação e cooperação nas ações e decisões; (...)."

${ }^{12}$ Ainda a multicitada apresentação da 2a . Conferência Nacional das Cidades: "(...) e) Canais de participação da sociedade na elaboração de orçamentos públicos, como planos plurianuais, leis de diretrizes orçamentárias e planos de todas as temáticas de forma integrada.(...)'

${ }^{13}$ Destaque-se o retrocesso registrado por MATTOS, Liana Portilho, em artigo intitulado "Da gestão democrática da cidade" (In: (Org.). Estatuto da Cidade comentado. Belo Horizonte: Mandamentos, 2002): 
ferências Públicas e os Conselhos Populares e Deliberativos, fazendo de tais lugares o locus de decisão consciente acerca das políticas públicas eficazes na transformação dos espaços urbanos, de forma a incluir todos os habitantes das cidades de maneira humana e verdadeiramente digna.

A busca da efetividade ${ }^{14}$ da participação da população na construção de uma gestão urbana amplamente democrática — que ouse render homenagem à soberania popular, consagrada pela Carta da República, que instituiu no Estado brasileiro uma Democracia participativa, ${ }^{15} \mathrm{em}$ que o poder é exercido diretamente pelo povo, nos termos em que ela preconiza ${ }^{16}-$ é tarefa de todos os participantes da cena social, mas, sobretudo, é missão daqueles que atuam no cenário jurídico.

Assim, a Carta Federal, ao prescrever que "a política de desenvolvimento urbano, executada pelo Poder Público municipal, conforme diretrizes gerais fixadas em lei, tem por objetivo ordenar o pleno desenvolvimento das funções sociais da cidade e garantir o bem-estar de seus habitantes", remeteu à legislação infraconstitucional a regulamentação da formulação, planejamento e execução da política nacional de desenvolvimento urbano, sendo que o Estatuto da Cidade, ${ }^{17}$ que veio dispor as regras gerais sobre a matéria, plasmou a gestão democrática da cidade, como diretriz geral a ser inelutavelmente seguida, e ainda, como instrumento de política urbana, nas várias formas criadas e aptas à inclusão dos habitantes na gestão da cidade.

O tema está, pois — a partir da Constituição Federal de 1988 e em especial, desde a edição do Estatuto da Cidade (Lei n. 10.257/01) —, na

"(...) a garantia da gestão democrática da cidade foi afrontada pelo vento oposto ao inciso I, do artigo 52, pelo qual se previa como crime de improbidade administrativa a conduta do prefeito que impedisse ou deixasse de garantir a participação de comunidades, movimentos e entidades da sociedade civil, conforme o disposto no $\S 3^{\circ}$ do artigo $4^{\circ}$ do Estatuto, pois, tristemente, a tradição brasileira tem demonstrado existir um vínculo significativo entre a eficácia das normas e a força das sanções correspondentes para o caso de seu descumprimento. (...)."

${ }^{14}$ Cf. BARROSO, Luís Roberto. Interpretação e aplicação da Constituição. 3. ed. São Paulo: Saraiva, 1999. p. 235-238: "(...) A idéia de efetividade, conquanto de desenvolvimento relativamente recente, traduz a mais notável preocupação do constitucionalismo nos últimos tempos. Ligada ao fenômeno da juridicização da Constituição, e ao reconhecimento e incremento de sua força normativa, a efetividade merece capítulo obrigatório na interpretação constitucional. Os grandes autores da atualidade referem-se à necessidade de dar preferência, nos problemas constitucionais, aos pontos de vista que levem as normas a obter a máxima eficácia ante as circunstâncias de cada caso". E continua dizendo, que efetividade é a "eficácia social da norma. (...) A efetividade significa, portanto, a realização do Direito, o desempenho concreto de sua função social. Ela representa a materialização, no mundo dos fatos, dos preceitos legais e simboliza a aproximação, tão íntima quanto possível, entre o dever-ser normativo e o ser da realidade social".

${ }^{15}$ Além de representativa, por meio de eleição.

16 "Art. $1^{\circ}$ A República Federativa do Brasil, formada pela união indissolúvel dos Estados e Municípios e do Distrito Federal, constitui-se em Estado Democrático de Direito e tem como fundamentos: (omissis) Parágrafo único: Todo o poder emana do povo, que o exerce por meio de representantes eleitos ou diretamente, nos termos desta Constituição."

${ }^{17}$ Lei $n^{\circ}$ 10.257, de 10.07.2001, arts. $2^{\circ}$, II, 4º III, $f$ e 43 a 45, dentre outros adiante mencionados.

A \& C R. de Dir. Administrativo e Constitucional, Belo Horizonte, ano 6, n. 25, p. 95-108, jul./set. 2006 
agenda política-jurídica nacional, em ações de caráter legislativo e também administrativo, envolvendo os governos das 03 (três) esferas verticais de Poder, ${ }^{18}$ quais sejam, da União, dos Estados e, especialmente, dos Municípios brasileiros, bem assim, toda população e a sociedade organizada. ${ }^{19}$

Inegável, portanto, que o grande marco do direito ao desenvolvimento urbano com a garantia de bem-estar dos habitantes das cidades deuse, como se disse, com a Carta Cidadã, que cravou no artigo 182, que a política de desenvolvimento urbano tem por objetivo ordenar o pleno desenvolvimento das funções sociais da cidade e garantir o bem-estar de seus habitantes. ${ }^{20}$ Dá-se, assim, a constitucionalização do Direito Urbanístico ${ }^{21}$ e, portanto, do direito à cidade ${ }^{22}$ e nasce o conceito de função social da cidade, ${ }^{23}$ estabelecido em norma constitucional, e por isso, de insofismável aplicabilidade e eficácia, a assegurar o pleno desenvolvimento do espaço urbano, garantindo o bem-estar de seus habitantes.

\footnotetext{
${ }^{18}$ Acerca da questão federativa e participação popular, veja-se em MACIEL, Marco, no jornal Folha de S.Paulo, de 04 mar. 2005, p. A3, em artigo intitulado "Por uma federação de fato": "(...) o redesenho do modelo federativo. Este impõe, entre outras ações, reforçar a desconcentração e a descentralização, por intermédio do fortalecimento dos Estado e municípios e o exercício de uma democracia participativa. (....."

${ }^{19}$ Nesse sentido, o Governo Federal vem promovendo as CONFERÊNCIAS DAS CIDADES, nos três âmbitos federativos, sendo que, a segunda de caráter nacional será realizada em Brasília no início de dezembro, sob o tema Construindo a Política Nacional de Desenvolvimento Urbano, com a seguinte apresentação: "Em 1940 , cerca de $20 \%$ da população brasileira era urbana. Hoje, o índice é de quase $82 \%$, o que permite classificar o Brasil como um dos países mais urbanizados do planeta. Este crescimento em direção às cidades se deu, em grande parte, por falta de um marco regulatório de planejamento e controle de uso e ocupação do solo, bem como de um financiamento deficiente. O resultado é uma lista de problemas como déficit habitacional, falta de saneamento e infra-estrutura, trânsito deficiente, transporte desordenado e ocupação e uso ilegal do solo. O Governo Federal, no entanto, acredita que há saídas para o atual cenário e aposta em planejamento e articulação para construir e transformar as cidades brasileiras em espaços mais sustentáveis. As diretrizes deste processo serão discutidas durante a $2^{a}$ Conferência Nacional das Cidades, que ocorrerá de 30 de novembro a 3 de dezembro, em Brasília. Com o lema "Reforma Urbana: Cidade para todos", o encontro dá prosseguimento a um processo iniciado em 2003, ano em que foi realizada a $1{ }^{a}$ Conferência Nacional das Cidades e criado o Conselho das Cidades (ConCidades), empossado em 2004. De lá para cá, o tema foi debatido em todo o país e as propostas recolhidas serão sistematizadas nesta $2^{a}$ Conferência e servirão de base para a formulação da Política Nacional de Desenvolvimento Urbano (PNDU). Essa política, de Estado, norteará as ações dos poderes públicos e será o alicerce para a formulação de um Sistema Nacional de Desenvolvimento Urbano estável e reestruturador do urbano no País, preenchendo uma lacuna de mais de vinte anos. O Conselho das Cidades apontou quatro temas que refletem os quatro principais desafios para implantação da PNDU no País: Participação e controle social; Questão federativa; Política urbana regional e metropolitana e Financiamento do desenvolvimento urbano. Estes temas são a base da pauta da $2^{a}$ Conferência das Cidades e resultam das discussões do primeiro evento, centrado em políticas setoriais como habitação e política fundiária, saneamento ambiental, transporte e mobilidade urbana e planejamento territorial urbano. As questões em debate agora são ainda mais complexas que as do primeiro encontro, e por isso exigirão maior parceria e engajamento das esferas federal, estadual e municipal.Outras quatro campanhas temáticas no âmbito da PNDU também estão sendo discutidas e exigem fundamental apoio da sociedade: Planos Diretores Participativos, Fundo Nacional de Habitação de Interesse Social, Marco Regulatório do Saneamento Ambiental e Programa Brasileiro de Acessibilidade Urbana. Brasília, 24 de agosto de 2005. Marcio Fortes de Almeida. Ministro de Estado das Cidades. Acesso em: set. 2005. Disponível em: <http://www.cidades.gov.br>.
} 
Como os preceitos constitucionais dos artigos 182 e 183, CF, reclamavam intermediação legislativa para conferir a tais normas (de eficácia limitada) aplicabilidade plena, veio à luz, em 10 de julho de 2001, a Lei $\mathrm{n}^{\mathrm{o}}$ 10.257, denominado Estatuto da Cidade (art. $1^{\circ}$, parágrafo único), traçando as normas gerais de direito urbanístico (no exercício da competência legislativa concorrente da União, a teor do art. 24, I, e $\S 1^{\circ}, \mathrm{CF}$ ), regulamentando os dispositivos constitucionais que tratam da política urbana, estabelecendo-lhe as diretrizes para o desenvolvimento urbano (nos termos da competência administrativa afeta à União, art. 21, XX, CF) consistente nas Diretrizes Gerais, na criação de novos Instrumentos de Política Urbana, no Plano Diretor e na Gestão Democrática da Cidade, ${ }^{24}$ e ainda, disposições gerais.

É precisamente a gestão democrática da cidade o ponto nuclear deste ensaio, com o objetivo de desvendar como — de que formas, em quais condições, em que âmbitos - a participação popular deve ocorrer a fim de dar efetividade aos

${ }^{20}$ Cf. Carlos Ari Sundfeld: "A ruptura provocada pela instalação da Assembléia Constituinte, em 1986, acabou causando uma rápida evolução jurídica em certas matérias. O caso do direito urbanístico foi exemplar. Desde 1977, por iniciativa governamental, discutia-se uma proposta de Lei Nacional de Reforma Urbana, gerando forte resistência empresarial (a principal crítica jurídica foi a suposta falta de base constitucional para sua edição). Com a submissão do assunto ao Congresso Nacional, na forma do Projeto de Lei 775/1983, o debate se ampliou (v., por exemplo, as análises do projeto por Eros Roberto Grau, Direito Urbano, São Paulo, Ed. RT, 1983, p. 117 e ss., e Ricardo Pereira Lira, Elementos..., p. 173 e ss.), mas a tramitação ficou barrada. O impasse teve solução surpreendente em 1988: acabou-se incluindo na nova Constituição a essência daquilo que, na singela forma de projeto de lei ordinária, sequer conseguia ser discutido." (In: DALLARI, Adilson Abreu; FERRAZ, Sérgio (Org.). O Estatuto da Cidade e suas diretrizes gerais: Estatuto da Cidade (Comentários à Lei Federal 10.257/2001). São Paulo: Malheiros, 2002. p. 48).

${ }^{21}$ Idem: "O papel que a Constituição de 1988 implicitamente assinalou ao direito urbanístico é o de servir à definição e implementação da 'política de desenvolvimento urbano', a qual tem por finalidade 'ordenar o pleno desenvolvimento das funções sociais da cidade e garantir o bem-estar de seus habitantes" (art. 182, caput).", op. cit., p. 48.

${ }^{22}$ Cf. ROCHA, Julio Cesar de Sá da. Considerações jurídicas sobre a função ambiental da cidade. Revista de Direito Ambiental, n. 14, p. 109: "O pleno direito à cidade inclui o direito à vida com dignidade, à moradia, à alimentação, à saúde, à segurança, ao meio ambiente ecologicamente equilibrado. A efetivação da função social da cidade estabelece-se quando o direito à cidade pode ser exercido em sua plenitude, ou seja, a cidade cumpre sua função social quando os cidadãos possuem os direitos urbanos."

${ }^{23}$ Cf. FIORILlO, Celso Antonio Pacheco. Curso de direito ambiental brasileiro. São Paulo: Saraiva, 2000. p. 197: "(...) a função social da cidade é cumprida quando esta proporciona a seus habitantes o direito à vida, à segurança, à igualdade, à propriedade e à liberdade (CF, art. 50, caput), bem como quando garante a todos um piso vital mínimo, compreendido pelos direitos sociais à educação, à saúde, ao lazer, ao trabalho, à previdência social, à maternidade, à infância, à assistência aos desamparados, entre outros encartados no art. 6०."

${ }^{24}$ Cf. FIORILLO, 2002, p. 84: "(...) O capítulo IV rompe com a superada visão administrativa de "disciplinar"as cidades a partir de regramentos impostos tão somente pelo Poder Público. Baseado nos fundamentos constitucionais da pessoa humana (art. $1^{\circ}, \mathrm{III}$ ) bem como da cidadania (art. $1^{\circ}, \mathrm{II}$ ) e fixada através de diretriz contida na Lei 10.257/2001 (art. 2 , II), a gestão democrática da cidade (arts. 43 a 45) permite dar efetividade a tutela do meio ambiente artificial através da participação direta de brasileiros e estrangeiros residentes em nosso país o que será feito não só no âmbito institucional (art. 43, I) como através de iniciativa popular de projeto de lei (art.43, IV). 0 art. 43 não impede a utilização de outros instrumentos de controle ambiental a exemplo das ações coletivas visando a tutela jurisdicional em defesa de meio 
comandos legais (e constitucionais, já que se trata de norma integrativa a dar plena eficácia aos preceitos inscritos na Carta Federal acerca do desenvolvimento urbano) e alcançar a máxima eficácia no que refere à democratização da gestão urbana - não só das prescrições que já compõem o arcabouço normativo acerca da política de desenvolvimento urbano, como ainda pela ampliação dos meios e formas de realização do princípio constitucional da democracia participativa, ${ }^{25}$ através da participação direta da população nas instâncias de poder de decisão acerca das políticas públicas urbanísticas, ${ }^{26}$ dando ao povo poderes ativos de soberania militante e diuturna. ${ }^{27}$

Constitui, destarte, objetivo deste arrazoado, formular e desenvolver hipóteses de efetiva participação popular nas esferas governamentais, bem como nos espaços públicos não-estatais, descentralizando e ampliando os campos decisórios acerca da formulação, planejamento, execução e fiscalização das políticas públicas de desenvolvimento urbano, oferecendo, assim, a partir de outro vértice, outra ética e nova racionalidade, alternativas para uma efetiva gestão democrática participativa das cidades, ${ }^{28}$ numa constante construção do processo de participação e consolidação da Democracia.

ambiente artificial ecologicamente equilibrado que poderão ser manejadas pela população (vide nosso comentários aos artigos 53 e 54 do Estatuto da Cidade). Os debates, audiências e consultas públicas (art. 43, II), inclusive como condição obrigatória para sua aprovação pela Câmara Municipal (art. 44), atestam, sob o ponto de vista jurídico, a vontade do legislador de submeter ao próprio povo-livre de 'intermediários' institucionais - a gestão democrática da cidade."

${ }^{25}$ Não é demasiado lembrar, que se trata de princípio fundante do Estado Democrático de Direito brasileiro a teor do art. $1^{\circ}$, caput e parágrafo único, CF. Veja-se a respeito, o celebrado Professor Paulo Bonavides, em artigo publicado no jornal Folha de S.Paulo, de 29 out. 2005, Caderno A, p. 3-Tendências/debates, intitulado "Revolução participativa": "(..) A Carta parece importantíssima porque inaugurou no constitucionalismo republicano a era dos princípios, em que, por superioridade normativa, a legitimidade prepondera sobre a legalidade. (...) Em 1988, a Assembléia Constituinte escreveu e promulgou o princípio e as regras constitucionais que regem a presença popular na obra de governo. (...) A Constituição estabeleceu também os dois princípios-chave de nossa organização política: o princípio representativo e o princípio da democracia direta.(...) avulta a fórmula mais eficaz de consolidar a democracia participativa, contida na aprovação de uma emenda constitucional que sujeitasse a referendo as demais emendas de alcance institucional, e a plebiscito as questões fundamentais da governança democrática."

${ }^{26}$ Cf. FRANCISCO, 2001, p. 45: "(...) Como explicita, de modo sucinto, mas bem claro, o professor Walter Ceneviva, dentro da sistemática do Estatuto da Cidade, 'a participação do munícipe é permanente. Deve acompanhar e opinar até mesmo na instalação de atividades ou empreendimentos geradores de tráfego (o grande drama das maiores cidades, sobretudo perto das escolas).'(fr. Solo municipal em limites de uso, Folha de S.Paulo, 11.8.2001, Cotidiano, p. C-2). Dentro deste escopo, o Estatuto optou pela mitigação da democracia representativa, instituindo a participação direta da população das cidades na formulação da política urbana, dentro do próprio permissivo constitucional constante do art. $1^{\circ}$, parágrafo único da Carta Magna. (...)."

${ }^{27}$ Cf. ainda o Prof. Paulo Bonavides, em entrevista ao jornal Folha de S.Paulo, de 15 ago. 2005, Caderno A, p. 14, onde diz ainda, o eminente constitucionalista: "(...) A mudança possível é no sentido de transformar a democracia direta em democracia mais participativa, dando mais poder ao povo, mais presença deste na legitimação das tarefas de governo. (...) A desagregação moral dos quadros representativos nos conduz à necessidade de estabelecer, pelas vias constitucionais, a democracia participativa. (...)"

A \& C R. de Dir. Administrativo e Constitucional, Belo Horizonte, ano 6, n. 25, p. 95-108, jul./set. 2006 
Ainda, tendo em vista que o Estado Democrático de Direito é informado por princípios constitucionais, que norteiam o arcabouço normativo e constituem cânones aptos a assegurar os direitos dos cidadãos, a efetividade da participação popular na construção do desenvolvimento urbano passa, necessariamente, pela democracia participativa. ${ }^{29}$

A atualidade do tema verifica-se também no direito comparado, tendo sempre como destaque a participação popular na planificação urbana. ${ }^{30}$

Sendo ainda indispensável considerar que as teorias jurídicas democráticas do Estado de Direito e constitucional contemporâneo ${ }^{31}$ - com especial ênfase naquelas que contemplam a democracia participativa ${ }^{32} \mathrm{e}$ nos instrumentos de controle social $\mathrm{e}^{33}$ participação direta da população

\footnotetext{
${ }^{28}$ Confira-se em COMPARATO, Fábio Konder, no jornal Folha de S.Paulo, de 05 ago. 2005, p. A-3, em artigo intitulado "Democracia direta já!": "(..) Ninguém contesta que a representação popular é indispensável no funcionamento das democracias modernas. Mas seria um erro trágico desconhecer que o cerne do regime democrático está na soberania popular efetiva, e não meramente simbólica. Ora, soberania popular efetiva significa dar voz e voto ao povo, não só para eleger os governantes mas também e sobretudo para decidir diretamente as grandes questões socioeconômicas do país e controlar a ação de todos os agentes públicos.(...)."

${ }^{29}$ Confira-se, mais uma vez, o sempre festejado Professor Paulo Bonavides, no já mencionado artigo publicado no jornal Folha de S.Paulo, de 29 out. 2005, Caderno A, p. 3-Tendências/debates, intitulado "Revolução participativa": "(...) O futuro pertence, pois, à democracia participativa. "

${ }^{30}$ Como referência sobre o tema no direito comparado, aponta-se o que apresenta o alcalde de Palencia (Espanã), em artigo intitulado "Participación ciudadana y urbanismo". In: ORDENACIÓN del territori y desarrollo sostenible. Ciudad Argentina: Editorial de Ciência y Cultura: Buenos Aires, 2004. p. 214-215: "(...) La nueva concepción del urbanismo debe afianzarse em la doble lógica de la rehabilitación del território que solo se puede producir desde la proximidad y com la participación activa de los tejidos sociales sobre los que se actúa y sobre los que se pretende incidir. Solo de esta manera se pueden redisenãr lãs relaciones sociales, econômicas y culturales que se producen en el território. Se trata de establecer los puentes necesarios para llegar al futuro esperado y deseado por los habitantes del município, rompiendo com los modelos racionalistas de princípios de siglo y las intervenciones puramente especulativas. Por ello, se comparte la interpretacíon generalmente extendida del concepto de participacíon ciudadana em relacíon com el urbanismo entendida como uma intervención activa, basada em el empleo de liderazgos locales y organizaciones representativas de diferentes grupos de interés, orientada a la mejor adecuacíon del urbanismo al interés de la comunidad especificamente representada e, idealmente, al interés público. Esta Idea de participación activa nos lleva a hacer realidade otro principio que es fundamental: el urbanismo democrático o el urbanismo com el ciudadano, que se presupone por parte de las personas involucradas voluntad para buscar, em colaboración, el interés general. La defensa de um urbanismo participativo tiene además uma serie de efectos positivos entre los que podemos destacar por su importância los siguientes: - Crea legitimidad. La participacíon ciudadana en los processos urbanísticos aumenta la legitimidad de la actuación pública y la implicación en los temas colectivos - Incrementa la eficacia. Si los ciudadanos intervienen en el disenõ de la ciudad, se desarrollará más facilmente la política urbanística y, de este modo, se evitará que la ordenación definida se convierta em um papel estéril. - Los ciudadanos están, em general, más familiarizados que los urbanistas con las circunstancias específicas de las localidades donde viven y pueden, por tanto, hacer uma contribuición positiva a la base informativa de formulación de planes y desarrollo de alternativas para su ejecución." Anote-se, ainda, DROMI, Laura San Martino de, em artigo intitulado "Los cauces de la participacíon ciudadana". In: op. cit., p. 263-273: "El estado de derecho democrático exige como dato de su identidad la participación como forma de compromiso del habitante y principalmente del ciudadano em todas sus dimensiones. El individuo aislado, ocupado solo del 'yo', há tomado conciencia de que debe ocuparse tambíen del 'nosotros', com el cual se juega su destino final. Que el individuo sea parte de la cosa pública exige quebrar la indiferencia social y la apatia política através de la participación y el protagonismo. La participacíon ciudadana es la causa eficiente de la democracia. Para ejercer la ciudadana debe existir el derecho - deber a la partcipacíon y, en este orden, la participación ciudadana importa el derecho de los ciudadanos a ser actores em las propuestas, disenõ,implementación y evaluación de las políticas públicas. Por ello, se puede conceptuar
}

A \& C R. de Dir. Administrativo e Constitucional, Belo Horizonte, ano 6, n. 25, p. 95-108, jul./set. 2006 
nas decisões políticas ${ }^{34}$ — são fundamentais e propiciam o amálgama indispensável na construção dos caminhos que deságüem nas gestões efetivamente democráticas das cidades, assegurando o bem-estar de seus habitantes por meio do pleno desenvolvimento de suas funções sociais. ${ }^{35}$

De igual forma, a teorética constitucional principiológica, bem assim o ordenamento constitucional brasileiro e o arcabouço legal pátrio ${ }^{36}$ constituem marcos a partir dos quais pode-se buscar a expansão das for-

el valor participación ciudadana como la intervención organizada de la ciudadanía em la actividade pública, como manifestación de sus intereses sociales. (..) Em definitiva, como vemos, los caminos de la participación son la medida del compromiso, son los que dan vigencia y convivencia com calidad de vida a la organización social."

${ }^{31}$ Ao tratar do tema, CANOTILHO, 1998, p. 1255-1265, apresenta as (i) Teorias da Democracia: a teoria democrático-pluralista, a teoria elitista da democracia, a teoria da democracia do 'ordo-liberalismo'; e as (ii) Teorias Normativas da Democracia: teoria liberal, concepção republicana, democracia deliberativa, democracia discursiva e democracia corporativa; por derradeiro, apresenta uma (iii) Concepção Minimalista de Democracia. Esta última é a que melhor fundamentação dá ao tema proposto, veja-se: "Uma série de autores tem investigado o conjunto de regras, requisitos e instituições para se poder falar em 'estado democrático'. Trata-se do problema hoje conhecido sob o nome de democracia mínima. Em termos considerados paradigmáticos, um conhecido publicista italiano resumiu a questão elencando os tópicos básicos da democracia: A democracia distingue-se de todas as formas de governo autocráticos porque se caracteriza por um sistema de regras, primárias e fundamentais, que estabelecem: quem está autorizado a tomar decisões colectivas; quais os processos para essa tomada de decisões. De um modo mais informativo, uma definição mínima de democracia implica: (a) participação de um número tão elevado de cidadãos quanto possível; (b) regra da maioria para a tomada de decisões colectivas e vinculantes; (c) existência de alternativas reais e sérias que permitam opções aos cidadãos de escolher entre governantes e programas políticos; (d) garantias de direitos de liberdade e participação política. Estes requisitos mínimos estão reunidos no estado de direito democrático. É pouco provável que exista um estado que não seja um estado liberal de direito quanto à existência e preexistência destes direitos e funcionamento da democracia. É pouco provável que um estado não democrático esteja em condições de garantir as liberdades fundamentais.' Todavia, também a Democracia deliberativa, integrante das Teorias Normativas da Democracia, fundamenta o presente trabalho. Confira-se: "(...) A categoria conceitual mais importante é a de política deliberativa. A deliberação pressupõe uma concepção dialógica da política e a consideração desta como um processo racional de discussão dos ploblemas e alternativas de forma a obterem-se soluções justas, boas, ou, pelo menos, razoáveis, de ordenação da vida comunitária. A política serve para deliberar sobre a ordenação comunitária e não apenas para fornecer aberturas processuais à prossecução de interesses privados ou à optimização de preferências subjetivas."

32 Tome-se a exemplo, a teoria esposada pelo Professor José Afonso da Silva (Curso de direito constitucional positivo. 24. ed. São Paulo: Malheiros, 2005. p. 141 et seq.): "(...) O princípio participativo caracterizase pela participação direta e pessoal da cidadania na formação dos atos de governo. (...)."

${ }^{33}$ Lê-se em BRITO, Carlos Ayres. Em artigo intitulado "Distinção entre 'controle social de poder' e 'participação popular'". Revista Trimestral de Direito Público, v. 2, p. 85, 1993: "(...) a participação popular somente pode existir com a pessoa privada (individual ou associadamente) exercendo o poder de criar norma jurídica estatal, que é norma imputável à autoria e ao dever de acatamento de toda a coletividade. É igual a dizer: com a pessoa privada influindo constitutivamente na formação da vontade normativa do Estado, que assim é que se desempenha o poder político. (...) a participação popular não quebra o monopólio estatal da produção do Direito de forma emparceirada com os particulares (individual e coletivamente). E é justamente esse modo emparceirado de trabalhar o fenômeno jurídico, no plano da sua criação, que se pode entender a locução "Estado Democrático"(figurante no preâmbulo da Carta de Outubro) como sinônimo perfeito de "Estado Participativo. (...).".

${ }^{34}$ Veja-se em DALLARI, Adilson de Abreu. Em artigo intitulado "Instrumentos da política urbana". In: Estatuto da Cidade (Comentários à Lei Federal 10.257/2001). São Paulo: Malheiros, 2002. p. 82: "(...) na enumeração constante de seu inciso $\mathrm{V}, \mathrm{o}$ art. $4^{\circ}$ menciona o referendo e o plebiscito, que são instrumentos de realização do princípio participativo, também afirmado pela Constituição Federal.(...)." E ainda, à p. 302 "(...) A participação da população na implementação de empreendimentos ou atividades não foi reconhecida apenas como regra, mas também como princípio. (...)." 
mas e âmbitos de participação popular, ${ }^{37}$ bem assim a melhoria na qualidade da inclusão popular, a fim de garantir a efetiva gestão democrática das cidades.

Desde logo, como contribuição ao tema, é possível formular as seguintes proposições, com o escopo de ampliar os âmbitos de participação e atuação dos habitantes das cidades nas políticas públicas de desenvolvimento urbano, buscando assegurar, assim, a efetiva democratização na gestão das cidades:

(i) a iniciativa popular de emenda constitucional em todas as matérias que envolvam o pleno desenvolvimento das funções sociais da cidade e visem garantir o bem-estar de seus habitantes;

(ii) desobstrução das leis vigentes que tratam da iniciativa popular de lei, do plebiscito e do referendo, no sentido de minimizar as exigências para a eficaz utilização de tais instrumentos de democracia participativa na questão urbana;

(iii) a vinculatividade das decisões dos Conselhos das Cidades

\footnotetext{
${ }^{35}$ No escólio de MOREIRA NETO, 2001, p. 196-197: "(...) A descentralização social, sempre que seja possível e recomendável traz consigo as vantagens reconhecidas à participação cidadã, gênero do qual é espécie, contribuindo para a legitimidade corrente e finalística do emprego do poder estatal. Em última análise, é a cidadania que se realiza através dela. Nem por outro motivo AUGUSTÍN GORDILLO, estudioso rioplatense da participação política, apoiando-se em outros administrativistas do porte de ZAMPETTI e de SANCHEZ MORÓN, estabelece uma sinonímia entre democracia e participação e nos adverte que 'todas as sociedades desenvolvidas têm mais sistemas participativos de diferentes tipos que as subdesenvolvidas. (...)"

${ }^{36}$ Cf. FERNANDES, Edésio. Em artigo intitulado "Um novo estatuto para as cidades brasileiras". In: OSÓRIO, L. M. (Org.). Estatuto da Cidade e reforma urbana: novas perspectivas para as cidades brasileiras. Porto Alegre: Sergio Antonio Fabris Ed., 2002. p. 10-11: "(...) Outra dimensão fundamental do Estatuto da Cidade, novamente consolidando e ampliando a proposta básica da Constituição Federal de 1988, diz respeito à necessidade de os municípios promoverem a devida integração entre planejamento, legislação e gestão urbana, de forma a democratizar o processo de tomada de decisões e assim legitimar plenamente uma nova ordem jurídico-urbanística de natureza social. O reconhecimento pelos municípios de processos e mecanismos jurídico-políticos adequados que garantam a participação efetiva dos cidadãos e associações representativas no processo de formulação e implementação do planejamento urbano e das políticas públicas - através de audiências, consultas, conselhos, estudos de impactos de vizinhança, iniciativa popular na propositura de leis e sobretudo através das práticas do orçamento participativo - é tido pelo Estatuto da Cidade como sendo essencial para a promoção da gestão democrática das cidades. (...)"

${ }^{37}$ Veja-se em SAULE JÚNIOR, Nelson, em artigo intitulado "Estatuto da Cidade e o Plano Diretor: possibilidades de uma nova ordem legal urbana justa e democrática". In: OSÓRIO, L. M. (Org.). Estatuto da Cidade e reforma urbana: novas perspectivas para as cidades brasileiras. Porto Alegre: Sergio Antonio Fabris Ed. 2002: "(...) O respeito ao direito à participação significa o estabelecimento de mecanismos de participação para todas as fases do processo do plano diretor, desde o direito de iniciativa popular, de apresentação de propostas e emendas ao plano, de audiências públicas como requisito obrigatório, de consultas públicas através de referendo ou plebiscito mediante a solicitação da comunidade. (...) O princípio da participação popular tem como elemento para identificar o cumprimento do exercício do direito à igualdade, pois não pode haver exclusão de qualquer segmento da sociedade nos processos de tomada de decisões de interesse da coletividade. Portanto, qualquer pessoa humana e em especial os grupos sociais marginalizados têm o direito de participar do processo de planejamento municipal, portanto do processo do plano diretor. (...)."
}

A \& C R. de Dir. Administrativo e Constitucional, Belo Horizonte, ano 6, n. 25, p. 95-108, jul./set. 2006 
(Nacional, Estaduais, Regionais e Municipais) aos Poderes Públicos, bem assim o caráter permanente e a composição paritária (sociedade civil e poderes públicos) de tais instâncias;

(iv) a prioridade no estabelecimento de parcerias com a iniciativa privada para a execução dos planos e programas visando o desenvolvimento sustentável das cidades;

(v) a primazia na formulação de projetos, inclusive legislativos, que visem assegurar a função social da propriedade urbana, em proveito de toda a comunidade, em especial, no que respeita à preservação do patrimônio histórico, cultural, artístico e paisagístico da cidade;

(vi) destinação de recursos orçamentários para a publicidade das questões relativas ao desenvolvimento urbano, com a divulgação e acessibilidade das informações e transparência nas ações desenvolvidas, visando atingir toda a população, de forma a legitimar e convalidar as políticas urbanas;

(vii) o custeio, com recursos orçamentários, da participação popular nos eventos públicos onde se travem debates sobre o tema (debates, consultas, conferências, seminários, audiências, conselhos, entre outras formas de reunião) e

(viii) educação urbana, por meio da capacitação e formação dos habitantes das cidades, tornando-os aptos a influir de maneira efetiva nos processos referentes ao desenvolvimento da política urbana, de forma consciente e construtiva.

\section{Obras consultadas e/ou referidas}

ALEXY, Robert. Teoria de los derechos fundamentales. Madrid: Centro de Estudios Constitucionales, 1997.

ANDRADE, José Carlos Vieira de. Os direitos fundamentais na Constituição Portuguesa de 1976. Coimbra: Almedina, 1987.

BARROSO, Luís Roberto. Interpretação e aplicação da Constituição. São Paulo: Saraiva, 1996.

BARROSO, Luís Roberto. O começo da história. A nova interpretação constitucional e o papel dos princípios no direito brasileiro. Revista de Direito Administrativo, Rio de Janeiro, n. 232, p. 141-176, abr./jun. 2003.

BONAVIDES, Paulo. Curso de direito constitucional. São Paulo: Malheiros, 2004.

BRASIL. Ministério das Cidades. Disponível em: < http://www.cidades.gov.br>

A \& C R. de Dir. Administrativo e Constitucional, Belo Horizonte, ano 6, n. 25, p. 95-108, jul./set. 2006 
CANOTILHO, J. J. Gomes. Direito constitucional e Teoria da Constituição. Coimbra: Almedina, 1998.

CANOTILHO, J.J. Gomes; MOREIRA, Vital. Fundamentos da Constituição. Coimbra: Coimbra Ed., 1991.

COSTA, Juliana Pedrosa. Gestão Democrática das Cidades. Revista de Direito Municipal, Belo Horizonte, ano 5, n. 13, p. 81-102, jul./set. 2004.

DALLARI, Adilson Abreu; FERRAZ, Sérgio (Org.). Estatuto da Cidade. São Paulo: Malheiros, 2002.

DROMI, Laura San Martino de. Los cauces de la participación cidadana. In: ORDENACIÓN del território y desarrollo sostenible. Buenos Aires: Ciudad Argentina Ed. de Ciência y Cultura, 2004. p. 263-273.

DWORKIN, Ronald. Los derechos en serio. Barcelona: Ariel, 1997.

FIORILLO, Celso Antonio Pacheco. Estatuto da Cidade comentado. São Paulo: R. dos Tribunais, 2002.

FOLHA DE S.PAULO, São Paulo. Disponível em: <www.folha.uol.com.br>.

FRANCISCO, Caramuru Afonso. Estatuto da Cidade comentado. São Paulo: Juarez de Oliveira, 2001 .

GALLEGO, Heliodoro. Participación ciudadana y urbanismo. In: ORDENACIÓN del território y desarrollo sostenible. Buenos Aires: Ciudad Argentina Ed. de Ciência y Cultura, 2004. p. 213-217.

GARCIA ENTERRIA, E. La Constitución como norma y el Tribunal Constitucional. Madrid: Civitas, 1991.

HABERMAS, Jürgen. Direito e democracia: entre facticidade e validade I. Rio de Janeiro: Tempo Brasileiro, 1997.

HESSE, Konrad. A força normativa da Constituição. Porto Alegre: Sergio Antonio Fabris Ed., 1991.

HESSE, Konrad. Escritos de derecho constitucional. Madri: Centro de Estúdios Constitucionales, 1992.

MARQUES, José Roberto Marques. Meio ambiente urbano. Rio de Janeiro: Forense Universitária, 2005.

MATTOS, Liana Portilho (Org.). Estatuto da Cidade comentado. Belo Horizonte: Mandamentos, 2002.

MOREIRA NETO, Diogo de Figueiredo. Mutações do direito administrativo. Rio de Janeiro: Renovar, 2001.

MÜLLER, Friedrich. Concepções modernas e a interpretação dos direitos humanos. In: ENCONTRO NACIONAL DA OAB, 14, 1997, Fortaleza. Conferência proferida.

OSORIO, Letícia Marques. Estatuto da Cidade de Reforma Urbana: novas perspectivas para as cidades brasileiras. Porto Alegre: Sergio Antonio Fabris Ed., 2002.

PATARO, Gustavo. O município como lugar ideal para estabelecimento de uma relação dialógica entre o poder e o povo. Revista de Direito Municipal, Belo Horizonte, n. 8, p. 97$127,2003$.

A \& C R. de Dir. Administrativo e Constitucional, Belo Horizonte, ano 6, n. 25, p. 95-108, jul./set. 2006 
SARLET, Ingo Wolfgang. Dignidade da pessoa humana e direitos fundamentais na Constituição Federal de 1988. Porto Alegre: Liv. do Advogado, 2001.

SARLET, Ingo Wolfgang. A eficácia dos direitos fundamentais. Porto Alegre: Liv. do Advogado, 2001.

SAULE JÚNIOR, Nelson. Novas perspectivas do direito urbanístico brasileiro: ordenamento constitucional da política urbana: aplicação e eficácia do Plano Diretor. Porto Alegre: Sergio Antonio Fabris Ed., 1997.

SILVA, José Afonso da. Aplicabilidade das normas constitucionais. São Paulo: Malheiros, 1998.

SILVA, José Afonso da. Curso de direito constitucional positivo. São Paulo: Malheiros, 2005.

Informação bibliográfica deste texto, conforme a NBR 6023:2002 da Associação Brasileira de Normas Técnicas (ABNT):

RAMOS, Marcelene Carvalho da Silva. Participação popular como condição de efetividade da gestão urbano-democrática. A\&C Revista de Direito Administrativo e Constitucional, Belo Horizonte, ano 6, n. 25, p. 95-108, jul./set. 2006. 